\title{
Evaluation of Rubus genetic resources on their resistance to cane disease
}

\author{
Vadim Girichev • Marcel von Reth · Magda-Viola Hanke • Monika Höfer • \\ Erik Schulte $\cdot$ Henryk Flachowsky id
}

Received: 29 January 2018/ Accepted: 3 July 2018/Published online: 25 July 2018

(C) The Author(s) 2018

\begin{abstract}
Raspberry cane disease, caused by a complex of fungi, is amongst the most devastating problems for raspberry production. Using resistant or highly tolerant genotypes is a promising strategy. However, until now, cultivars with good field resistance for German fruit growers as well as the primary causal pathogens of cane disease present in the eastern part of Germany, Saxony state are still unknown. The primary objective of this study was to identify the primary disease causing organisms and resistant Rubus germplasm for future breeding efforts. From 2012 to 2014, we evaluated the degree of susceptibility to cane diseases on 213 raspberry cultivars at two different locations using a rating scale. We also
\end{abstract}

Electronic supplementary material The online version of this article (https://doi.org/10.1007/s10722-018-0670-1) contains supplementary material, which is available to authorized users.

Vadim Girichev and Marcel von Reth have contributed equally to this work.

V. Girichev · M. von Reth · M.-V. Hanke .

M. Höfer · H. Flachowsky ( $\square)$

Julius Kühn-Institut (JKI), Federal Research Centre for Cultivated Plants, Institute for Breeding Research on Fruit Crops, Pillnitzer Platz 3a, 01326 Dresden, Germany

e-mail: henryk.flachowsky@julius-kuehn.de

E. Schulte

Federal Office of Plant Varieties, Torgauer Straße 100, 04808 Wurzen, Germany identified the main fungi growing on infected canes. Our results suggest that Fusarium avenaceum is the main fungus causing cane disease in Saxony. The Rubus hybrid cultivars 'Tayberry' $(2 n=6 x=42)$, 'Buckingham Tayberry' $(2 n=6 x=42)$ and 'Dorman Red' $(2 n=2 x=14)$ displayed the highest levels of field resistance at both locations. Moreover, we established an in vitro assay for resistance evaluation which correlates significantly with field data and is particularly suitable for quick assessment of resistance against $F$. avenaceum in breeding material. Future breeding programs, aiming at cultivars with enhanced resistance towards cane diseases can use the presented data for parental selection and may employ our in vitro $F$. avenaceum inoculation method for parental testing and progeny selection.

Keywords Rubus idaeus - Genetic resources · Cane diseases · Cane blight · Resistance breeding ·

Fusarium avenaceum

\section{Introduction}

In 2016, the worldwide production of raspberries amounted to $795,249 \mathrm{t}$, with about $75 \%(498,353 \mathrm{t})$ produced in Europe (Faostat 2016). Currently, main raspberry producing countries are Russia, Poland, and Serbia. In Germany, raspberry production decreased 
from $29,700 \mathrm{t}$ in 2002 to $5617 \mathrm{t}$ in 2016 , despite the overall increase in the worldwide raspberry production (Faostat 2016). This phenomenon is the result of multiple factors, including high production costs, increased labor costs and an increase in the occurrence of several plant diseases, including black root rot, the spread of fungicide-resistant Botrytis strains and cane diseases (Graham et al. 2011; Rupp et al. 2016). Raspberry cane disease is caused by various phytopathogenic fungi, including Fusarium avenaceum (Fusarium wilt), Didymella applanata (spur blight), Leptosphaeria coniothyrium (cane blight) and Botrytis cinerea (cane Botrytis) with $F$. avenaceum being the major cause of cane diseases in Northern Germany (Williamson and Hargreaves 1979; Weber and Entrop 2008). First pink to orange colored spore bearing structures on dark brown lesions which are clear indications of infections of young raspberry primocanes with $F$. avenaceum can be found at the end of May beginning of June at earliest depending on the year and weather conditions (Weber and Entrop 2008). Afterwards disease symptoms are progressing until the end of August, beginning of September.

However, diseased canes in the field are often infected by a complex of several of these fungi, making it difficult to pin down the primary causal pathogen from infection symptoms alone. The infection may be associated with "midge blight" caused by the cane midge Resseliella theobaldi. However, this might not necessarily be the case (Williamson and Hargreaves 1979; Weber and Entrop 2008). Hence, we will generalize the disease complex as 'cane disease' throughout this manuscript without further specification.

As a result of an infection, fungal pathogens occupy the vascular system and block water and nutrient transport. Infected canes become weakened and die. The consequence is that raspberry plantations quickly become unprofitable, thus emphasizing the need for cultivars with resistance to cane disease. Cultivars combining field resistance to cane disease with superior fruit traits such as large fruit size, sufficient firmness, excellent taste and a beautiful shape are currently not available. Breeding of new and highly resistant cultivars is therefore a major aim in many raspberry breeding programs.

Despite the widespread occurrence of this disease complex and its impact on the raspberry industry, detailed studies concerning the identification of sources for field resistance in raspberry germplasm collections or in related Rubus species are still missing. This includes the identification of the primary causal pathogens in different areas in Germany. Until now, only northern Germany has been assessed (Weber and Entrop 2008). Moreover, artificial inoculation experiments for evaluating the resistance or susceptibility of germplasm have not been established.

Therefore, this study aimed at the identification of resistance sources using a collection of 213 different raspberry cultivars, including Rubus hybrid cultivars and other Rubus species. Because cane disease occurs in a complex, identification and introgression of pathogen strain-specific resistances into elite cultivars appears extremely difficult. Identification of sources for broad-spectrum or field resistance may be a more promising and durable strategy. Gene $H$, determining pubescence of raspberry canes is a prominent example for broad-spectrum resistance attributed to a single locus in raspberry. It has been shown to be linked with increased resistance towards Didymella applanata, Leptospaeria coniothyrium and Botrytis cinerea and comes at the cost of enhanced susceptibility towards Elsinoe veneta and Sphaerotheca macularis (Graham et al. 2006; Jennings 1962, 1982; Jennings and Brydon 1989a, b). Here, we screened the available genetic resources at two different locations in Saxony (East Germany) based on the severity of cane disease symptoms, without attributing symptoms to individual pathogens aiming at the identification of potential sources for broad-spectrum disease resistance. Furthermore, the priority was to identify the primary causal pathogens for Saxony (East Germany), one of the three major fruit production areas in Germany. For this purpose, a field trial was performed from 2012 to 2014 at two different locations. Additionally, we aimed at establishing a reliable inoculation method which allows the identification of resistant germplasm under standardized environmental conditions.

\section{Materials and methods}

Plant material and location

In total, 213 different Rubus genotypes were evaluated from 2012 to 2014 at two different locations grown according to standard horticultural practices. Most genotypes were red raspberries and belonged to Rubus 
idaeus L.. In addition the black raspberry ( $R$. occidentalis L.) genotype 'Black Jewel', the Rubus hybrid cultivars 'Tayberry', 'Buckingham Tayberry', 'Clen Coe', and 'Dorman Red', as well as the blackberry $(R$. fruticosus L.) cultivar 'Navaho' were also included into the study.

\section{Location 1}

Borthen, close to Dohna, Saxony (lat 50.968778, long 13.826466). This site is located within a commercial raspberry plantation which is used since many years. 'Tulameen' and 'Clen Ample' are the two main cultivars which are grown in this plantation. Both cultivars showed always a good level of infection with cane disease. The field trial planted for this study at this site consisted of cultivars commercially used in Germany at this time. Thirty-one Rubus cultivars were planted in 2012 in a randomized block design consisting of at least two blocks per cultivar. One block consisted of 20 plants of the same genotype. The cultivars 'Autumn Bliss', 'Lucana', 'Meeker', 'Niniane', 'Octavia', 'Malling Minerva', 'Royalty', 'Rumla' and 'Saxa Bliss' were planted as a single block, because only a small number of plants was commercially available in individual small nurseries. The plantation consisted of five rows and 15 blocks per row. 'Glen Ample' (Rubus idaeus, red raspberry) is the dominating cultivar for open field production in Germany. Hence, 'Glen Ample' was used as a reference cultivar and planted in the first and last blocks of each row and additionally in two random blocks within the plantation. The red raspberry cultivar 'Tulameen', known to be affected by cane diseases in Germany, was planted as a susceptible standard in a randomized design in three blocks per row to promote spreading of the naturally occurring fungal causal pathogens of cane disease in this plantation. This plantation was evaluated from 2012 to 2014 (Supplementary Table 1).

\section{Location 2}

Wurzen (Saxony) at the small fruit testing station of the Bundessortenamt (lat 51.372439, long 12.757139), $100 \mathrm{~km}$ away from location 1. An established genebank collection consisting of 200 different cultivars with single blocks of at least eight plants per genotype was used for evaluation. The collection exists since more than 10 years at this site and cane disease is well distributed among the cultivars. This genebank collection was evaluated in October of 2013 and 2014 (Supplementary Table 1).

Resistance evaluation in the field

In order to determine the level of cane disease infestation, we established a rating scale (Fig. S1). This scale was based on the percentage of visibly infected area per cane and consists of six classes namely: class 0 (very resistant, no infection), class 1 (resistant, up to $10 \%$ infected area), class 2 (medium resistant, 11-25\% infected area), class 3 (medium susceptible, 26-50\% infected area), class 4 (susceptible, $51-75 \%$ infected area) and class 5 (very susceptible, $>76 \%$ ).

Isolation and morphological characterization of fungal isolates

In October 2013, when the symptoms of cane disease were most pronounced, samples of diseased raspberry canes were randomly taken in the field from locations 1 and 2. In 2014, sampling was expanded to four time points (May, June, August and October) in order to analyze the seasonal distribution of fungi at location 1 (Supplementary Table 1). At each time point ten different places randomly distributed within the location were selected. From each place up to five diseased canes were taken for the isolation of fungal pathogens. Canes were cut into pieces of 3-5 cm and the infected tissue was isolated from lesion margins and placed in Petri dishes on Czapek Dox Agar (Duchefa, Haarlem, Netherlands) supplemented with $200 \mathrm{mg} / \mathrm{L}$ streptomycin and $200 \mathrm{mg} / \mathrm{L}$ penicillin. The Petri dishes were incubated under continuous light for 2 weeks at $24{ }^{\circ} \mathrm{C}$ and $70 \%$ relative humidity in a climatic cabinet. Thereafter, single conidiospores of the developing isolates were transferred onto Czapek Dox Agar without antibiotics and incubated for another 2 weeks under the previously described conditions. Single conidiospore isolates were then inspected macroscopically and microscopically. 
Molecular identification of fungal species

Fungal genomic DNA was extracted from each single conidiospore isolate using the DNeasy Plant Mini Kit (Qiagen, Hilden, Germany).

The identification of fungal species followed a twostep process. Firstly, PCR was performed using the ITS specific primers namely: ITS1 (5'-TCC GTA GGT GAA CCT GCG G-3') and ITS4 (5'-TCC TCC GCT TAT TGA TAT GC-3') according to White et al. (1990). PCR products were purified with the MinElute ${ }^{\circledR}$ PCR Purification Kit (Qiagen, Hilden, Germany) and sequenced. Sequencing was performed by Eurofins MWG Operon (Ebersberg, Germany), using the primers ITS1 and ITS4. The obtained sequences were used to perform a BLAST search in the NCBI database (https://blast.ncbi.nlm.nih.gov/Blast.cgi) using the blastn function to identify the isolated fungi on the genus level.

Secondly, PCR with species specific primers was performed for Fusarium (F. culmorum, F. sambucinum, F. oxysporum, F. equiseti and F. avenaceum) described by Mishra et al. (2003) as well as Alternaria alternata (Konstantinova et al. 2002), Botrytis cinerea (Rigotti et al. 2002) and D. applanata (Lindqvist-Kreuze et al. 2003) to identify these fungi on the species level. The primers used are listed in Supplementary Table 2.

\section{Resistance evaluation in vitro}

In total, 39 different Rubus genotypes (35 Rubus idaeus cultivars, 1 Rubus fruticosus cultivar and 3 Rubus hybrid cultivars) were evaluated in two consecutive years (2013 and 2014). For each genotype, 15 primocane pieces (approximately $10 \mathrm{~cm}$ in length and approximately $1.0-1.5 \mathrm{~cm}$ in diameter each) were cut and surface sterilized for $1 \mathrm{~min}$ with $70 \% \mathrm{v} / \mathrm{v}$ ethanol, then for another $3 \mathrm{~min}$ with $5 \% \mathrm{v} / \mathrm{v} \mathrm{NaOCl}$ and finally for $30 \mathrm{~s}$ with $70 \% \mathrm{v} / \mathrm{v}$ ethanol. To facilitate infection, a $1 \mathrm{~cm}$ long injury was made in the center of the canes with a scalpel, followed by inoculating the wound with $5 \mu \mathrm{L}$ of a $F$. avenaceum conidia suspension $\left(10^{6}\right.$ conidia/mL) and pricked upright $2 \mathrm{~cm}$ deep into full strength MS medium supplemented with vitamins (Duchefa, Haarlem, Netherlands), adding $30 \mathrm{~g} / \mathrm{L}$ saccharose, $0.3 \mathrm{mg} / \mathrm{L}$ benzyl adenine, $0.1 \mathrm{mg} / \mathrm{L}$ indole-3butyric acid, $0.2 \mathrm{mg} / \mathrm{L}$ gibberellic acid and $7 \mathrm{~g} / \mathrm{L}$ agar with a $\mathrm{pH}$ value adjusted to 5.8. After 5 days of incubation at $24{ }^{\circ} \mathrm{C}$, the canes were evaluated with the previously established, rating scale (Fig. S2). Two variables were taken into account to evaluate the resistance. Variable A describes blight symptoms as percentage of necrosis along the site of inoculation. The rating scale for this variable consists of six classes namely: classes 1 (no necrosis, very resistant), 2 (1-10\% necrotic area, resistant), 3 (11-30\% necrotic area, medium resistant), 4 (31-60\% necrotic area, medium susceptible), 5 (61-90\% necrotic area, susceptible,) and 6 ( $\geq 90 \%$ necrotic area, very susceptible). Variable B describes the extent of sporulation as percentage of sporulating tissue along the site of inoculation. The rating scale for variable $\mathrm{B}$ consists of six classes namely: classes 1 (no sporulation, very resistant), 2 (1-10\% sporulation, resistant), 3 (11-30\% sporulation, medium resistant), 4 (31-60\% sporulation, medium susceptible), 5 (61-90\% sporulation, susceptible), and 6 (>90\% sporulation, very susceptible). This experiment was repeated twice for all cultivars.

\section{Flow cytometry}

To analyze ploidy levels of germplasm used in this study, flow cytometry was performed according to Meng and Finn (2002).

\section{Statistics}

Pearson $r$-correlation was used in order to correlate average ratings for necrosis or sporulation obtained from in vitro inoculation with average field ratings from location 1 using the formula:

$r=\frac{N \sum x y-\sum(x)(y)}{\sqrt{\left[N \sum x^{2}-\sum\left(x^{2}\right)\right]\left[N \sum y^{2}-\sum\left(y^{2}\right)\right]}}$

where $\mathrm{r}=$ Pearson $r$-correlation coefficient; $\mathrm{N}=$ number of values in each data set; $\sum x y=$ sum of the products of paired scores; $\sum \mathrm{x}=$ sum of $\mathrm{x}$ scores; $\sum \mathrm{y}=$ sum of $\mathrm{y}$ scores; $\sum \mathrm{x}^{2}=$ sum of squared $\mathrm{x}$ scores and $\sum y^{2}=$ sum of squared y scores.

The level of significance of the correlation between two parameters was assessed with a Student's $t$ test. 


\section{Results}

Identification and seasonal distribution of cane associated fungi

Cane associated fungi were isolated as described and cultivated as single conidiospore isolates on agar plates. Subsequently all isolates were evaluated macroscopically and microscopically. Isolates representing the same phenotype were subjected to the same group. The partial ITS region of selected isolates per group was sequenced and blasted in the NCBI database. This allowed the assignment of isolates to fungal genera and often also to the most likely species. Species specific primers (if available) were used to verify the sequencing results. The investigated fungal isolates could be assigned to 24 different species and genera, respectively (Fig. S3). Sixteen out of these belonged to the class of Sordariomycetes, six belonged to dothideomycetes, one belonged to leotiomycetes and one belonged to zygomycetes (Table 1). Isolates belonging to Leptosphaeria and Botrytis dominated at the beginning of vegetation, whereas $F$. avenaceum and A. alternata clearly dominated in summer and autumn (Fig. 1). A comparison of the seasonal occurrence of fungal species on diseased raspberry canes showed that $F$. avenaceum, Leptosphaeria sp., D. applanata and Botrytis sp. were present at either location, whereas other fungal species were only present at one or the other location (Table 1).

Resistance evaluation at location 1 (2012-2014)

In total, 31 cultivars including the interspecific Rubus hybrid cultivars 'Tayberry', 'Buckingham Tayberry', 'Glen Coe', 'Dorman Red' and the Rubus occidentalis cultivar 'Black Jewel', were evaluated three times per year during the seasons of 2012-2014. A comparison of the mean value over all 3 years showed that the cultivars 'Dorman Red', 'Tayberry' and 'Buckingham
Table 1 Plant associated fungi detected on diseased raspberry canes at locations 1 and 2 in 2013 and 2014

\begin{tabular}{|c|c|c|c|}
\hline Class & Species & Location 1 & Location 2 \\
\hline \multirow[t]{16}{*}{ Sordariomycetes } & Bionectria ochroleuca $^{\mathrm{a}}$ & $\mathrm{x}$ & \\
\hline & Colletotrichum gloeosporioides ${ }^{\mathrm{a}}$ & & $\mathrm{x}$ \\
\hline & Fusaium asiaticum $^{\mathrm{a}}$ & $\mathrm{x}$ & $\mathrm{x}$ \\
\hline & Fusarium avenaceum $^{b}$ & $\mathrm{x}$ & $\mathrm{x}$ \\
\hline & Fusarium culmorum $^{b}$ & $\mathrm{X}$ & $\mathrm{x}$ \\
\hline & Fusarium equiseti $^{b}$ & $\mathrm{x}$ & $\mathrm{x}$ \\
\hline & Fusarium lateritium $^{\mathrm{a}}$ & $\mathrm{x}$ & \\
\hline & Fusarium oxysporum ${ }^{b}$ & $\mathrm{x}$ & \\
\hline & Fusarium poae & $\mathrm{x}$ & \\
\hline & Fusarium sambucinum $^{b}$ & $\mathrm{x}$ & $\mathrm{x}$ \\
\hline & Fusarium sporotrichioides $^{\mathrm{a}}$ & $\mathrm{x}$ & \\
\hline & Fusarium tricinctum $^{\mathrm{a}}$ & $\mathrm{x}$ & \\
\hline & Fusarium venenatum $^{\mathrm{a}}$ & $\mathrm{x}$ & \\
\hline & Phomopsis sp. & $\mathrm{x}$ & $\mathrm{x}$ \\
\hline & Phomopsis quercella ${ }^{\mathrm{a}}$ & $\mathrm{x}$ & \\
\hline & Truncatella angustata ${ }^{\mathrm{a}}$ & $\mathrm{x}$ & \\
\hline \multirow[t]{6}{*}{ Dothideomycetes } & Alternaria alternata ${ }^{b}$ & $\mathrm{x}$ & \\
\hline & Aureobasidium pullulans ${ }^{\mathrm{a}}$ & $\mathrm{x}$ & \\
\hline & Cladosporium sp. & $\mathrm{x}$ & \\
\hline & Didymella applanata ${ }^{b}$ & $\mathrm{x}$ & $\mathrm{x}$ \\
\hline & Epicoccum nigrum $^{\mathrm{a}}$ & $\mathrm{X}$ & \\
\hline & Leptosphaeria coniothyrium $^{\mathrm{a}}$ & $\mathrm{x}$ & $\mathrm{x}$ \\
\hline Leotiomycetes & Botrytis sp. & $\mathrm{x}$ & $\mathrm{x}$ \\
\hline Zygomycetes & Mucor circinelloides ${ }^{\mathrm{a}}$ & $\mathrm{X}$ & \\
\hline
\end{tabular}

${ }^{\mathrm{a}}$ These isolates were not unequivocally identified at the species level. They were evaluated macroscopically, microscopically and by sequencing of the partial ITS region. Based on blastn results obtained from the NCBI database the species given here is the most likely species

${ }^{b}$ Sequencing results were validated by PCR using species specific primers 

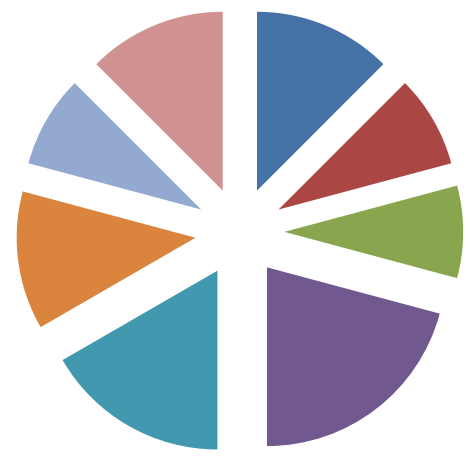

- Alternaria alternata

- Fusarium avenaceum

Aureobasidium pullulans *

- Leptosphaeria coniothyrium *

Botrytis sp.

Epicoccum nigrum *

Phomopsis quercella *

- Other species

May $(n=24)$
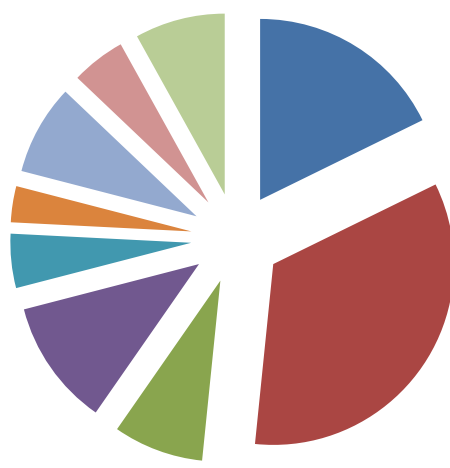

- Alternaria alternata

- Fusarium avenaceum

Phomopsis sp.

Leptosphaeria coniothyrium *

Botrytis sp.

- Fusarium tricinctum *

Dydimella applanata

Fusarium sambucinum

Other species

\section{August $(n=62)$}

Fig. 1 Seasonal distribution of individual fungi in the raspberry plantation at location 1, Borthen in 2014. Each pie chart depicts the proportion of individual fungal species identified at defined

Tayberry' were very resistant to cane disease at location 1. Other cultivars, such as 'Glen Coe', 'Black Jewel' and 'Gradina' were rated as resistant. 'Sanibelle', 'Malling Minerva', 'Rubaca'/Niniane ${ }^{\circledR}$ and 'Resa'/Lucana ${ }^{\circledR}$ were the most susceptible cultivars at this location (class $3=$ medium susceptible). The commercially most important floricane cultivars in German raspberry production 'Tulameen' (Score: 2.3) and 'Glen Ample' (Score: 2.6) were rated as medium resistant. The results are summarized in Fig. 2.

Resistance evaluation at location 2 (2013-2014)

Two hundred genotypes (traditional and modern cultivars) were scored for the occurrence of raspberry cane disease in October of each year. At this time point symptoms of cane disease on hardening primocanes are most pronounced. The cultivars 'Black Jewel' (0.5), 'Lowden' (0.7), 'Rubifall' (0.8) and 'Autumn Treasure' $(0.8)$ were rated as very resistant. The most

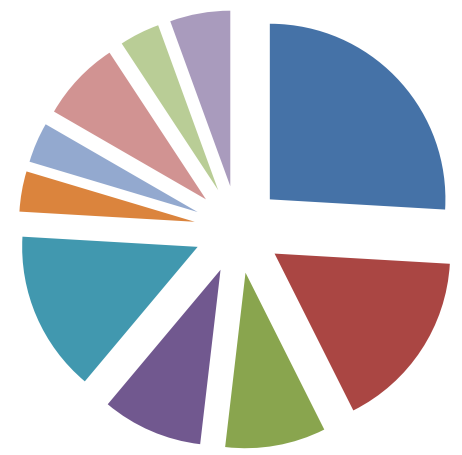

- Alternaria alternata

- Fusarium avenaceum

Aureobasidium pullulans *

- Leptosphaeria coniothyrium *

Botrytis sp

- Dydimella applanata

- Fusarium sambucinum

m Fusarium culmorum

Cladosporium sp.

- Other species

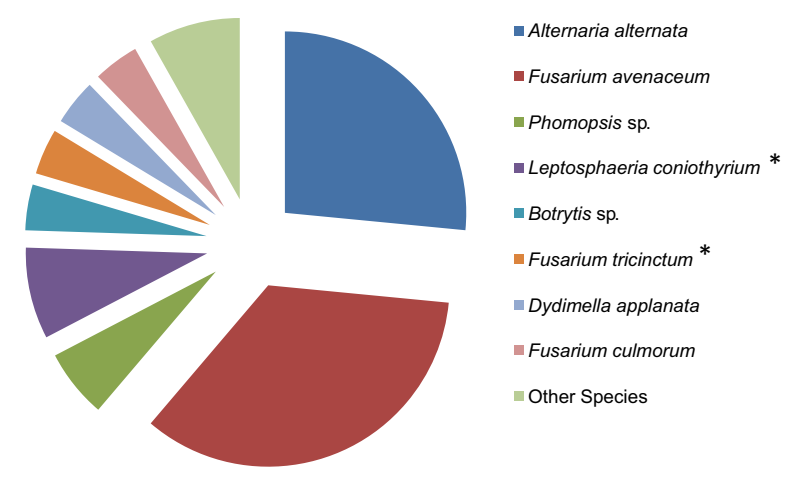

\section{October $(n=49)$}

time points during the year 2014. The number of samples taken from visually infected canes is given in parentheses (see also Supplementary Table 1)

susceptible cultivars were 'Chiliwak' (3.7), 'Madawaska' (3.8), 'Canby' (3.9), rated as medium susceptible and 'Delmes' (4.0), rated as susceptible. Similar to the situation at location 1 the cultivars 'Tulameen' and 'Glen Ample' were rated as medium resistant with scores of 2.4 and 2.5, respectively. Results for all raspberry cultivars evaluated at location 2 are summarized in Table 2. We labeled cultivars harbouring gene $H$, which determines cane pubescence. Historical reports attributed resistance towards $B$. cinerea, $D$. applanata and L. coniothyrium and susceptibility towards Elsinoe veneta and Sphaerotheca macularis to the presence of Gene $H$ (Graham et al. 2006; Jennings 1962, 1982; Jennings and Brydon 1989a, b). However, Gene $H$ positive cultivars were not among resistant cultivars in this survey (Table 2). 


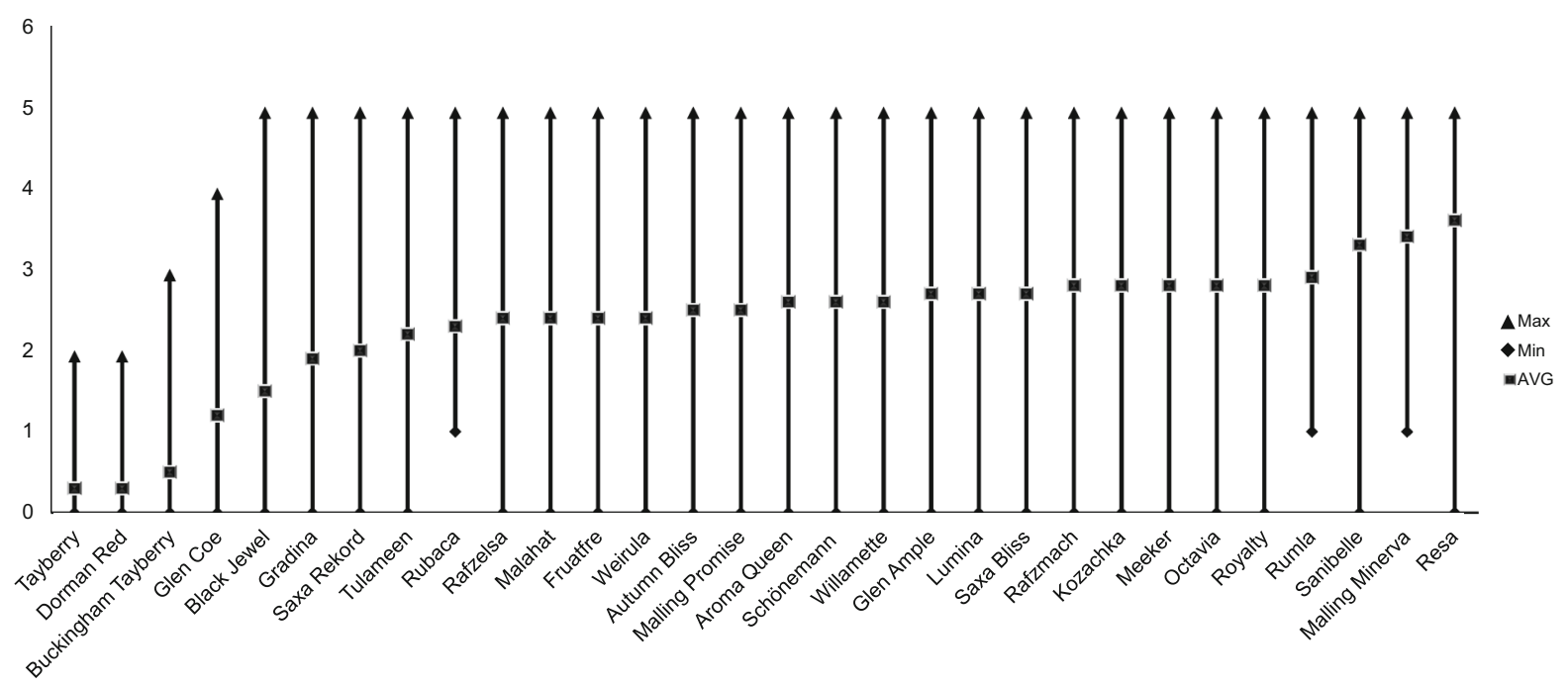

Fig. 2 Evaluation on resistance to cane disease (location 1, 2012-2014, see Supplementary Table 1). The rating was done in three consecutive years following natural infection. The $\mathrm{Y}$-axis shows rating values corresponding to the rating scale

In vitro inoculation with $F$. avenaceum

An in vitro assay was established allowing highthroughput evaluation of plants for resistance to $F$. avenaceum. Using this test, 39 different raspberry cultivars as well as two Tayberry cultivars, the blackberry cultivar 'Navaho' and the R. idaeus $\times R$. parvifolius hybrid cultivar 'Dorman Red' were evaluated in 2013 and 2014. Rating for the extent of necrosis and sporulation was done according to the ratings defined in Fig. S2. Both Tayberry cultivars 'Buckingham Tayberry' and 'Tayberry' as well as the blackberry cultivar 'Navaho' were mostly devoid of any symptoms with almost no necrotic lesions and a tendency towards sporulation of $\leq 10 \%$. No other genotype with similar levels of disease resistance was found. Nevertheless, some cultivars showed a low tendency towards necrosis, for example 'Glen Ample', 'Dorman Red', 'Golden Queen', 'Valentina', 'Fallgold', 'Octavia' and 'Autumn First'. The extent of sporulation was acceptable for 'Valentina', 'Fallgold' and 'Autumn First', whereas 'Octavia' allowed some sporulation (class 3) (Fig. 3).

Of the 39 cultivars tested in vitro, 28 cultivars were evaluated extensively at location 1 from 2012 to 2014 . We calculated the correlation between sporulation and necrosis accounted for in the in vitro inoculation test with field ratings from location 1 , as well as the defined in Supplementary Figure 1. Average values for the rating of each cultivar are shown in squares. Maximum and minimum rating values for each cultivar are depicted as triangles and diamonds, respectively

correlation of necrosis with sporulation. Both, sporulation (Fig. 4a) and necrosis (Fig. 4b) are significantly correlated with field data. Moreover, the correlation between necrosis and sporulation is highly significant as well (Fig. 4c).

\section{Determination of ploidy levels}

Differences in ploidy levels may impede the success of crosses. Therefore, we assessed ploidy levels of all Rubus genotypes available at the Julius Kühn-Institut in Dresden using a flow cytometer. The results are presented in (Table 3). Except for 'Tayberry' and 'Buckingham Tayberry', all other cultivars, including 'Dorman Red' were found to be diploid (Table 3).

\section{Discussion}

Genetic resources available for raspberry breeding have not been evaluated on a large scale in terms of resistance or susceptibility to raspberry cane disease occurring in Germany prior to this study. On the other hand, many pathogens account for various cane diseases in different areas throughout the world. To define which pathogens occur on diseased canes in field grown raspberries, either individually or in combination with others, we isolated and identified 
Table 2 Evaluation of 200 cultivars at location 2, the Bundessortenamt (Wurzen) from 2013 to 2014

\begin{tabular}{|c|c|c|c|c|c|c|c|}
\hline Cultivar & $\mathrm{AR}$ & $\Sigma$ Canes & $\Sigma$ Plants & Cultivar & $\mathrm{AR}$ & $\Sigma$ Canes & $\Sigma$ Plants \\
\hline Black Jewel & 0.5 & 17 & 6 & Bauer 26 & 2.7 & 79 & 14 \\
\hline Lowden & 0.7 & 68 & 11 & Marwes & 2.7 & 61 & 14 \\
\hline Rubifall & 0.8 & 107 & 14 & Neuheit II & 2.7 & 57 & 10 \\
\hline Autumn Treasure & 0.8 & 165 & 28 & Caroline & 2.7 & 134 & 24 \\
\hline TU1 & 1.1 & 86 & 18 & Unermüdliche & 2.7 & 84 & 16 \\
\hline Carmen & 1.1 & 137 & 27 & Baronne de Warve & 2.7 & 121 & 24 \\
\hline Deutschland 43 & 1.4 & 85 & 16 & Zefa3 & 2.7 & 49 & 12 \\
\hline Alpengold & 1.4 & 45 & 8 & Lloyd George & 2.7 & 146 & 26 \\
\hline Ontario & 1.5 & 95 & 18 & Malling Orion & 2.7 & 97 & 18 \\
\hline Trent & 1.5 & 84 & 16 & Geneva & 2.7 & 217 & 36 \\
\hline Heritage & 1.5 & 103 & 23 & Pujallup & 2.7 & 126 & 27 \\
\hline Schönemann & 1.7 & 107 & 25 & Goliath & 2.7 & 105 & 16 \\
\hline Festival & 1.7 & 135 & 20 & Boheme & 2.7 & 96 & 22 \\
\hline Sugana & 1.7 & 134 & 20 & Malling Jewel & 2.7 & 78 & 12 \\
\hline Glen Doll & 1.8 & 142 & 22 & Malling Exploit & 2.7 & 29 & 8 \\
\hline Superlativ & 1.8 & 152 & 22 & Rusilva & 2.7 & 222 & 44 \\
\hline Maurin Makea & 1.8 & 76 & 14 & Reveille & 2.8 & 73 & 14 \\
\hline Watson Rubi & 1.9 & 71 & 13 & Multiraspa & 2.8 & 85 & 16 \\
\hline Royalty & 1.9 & 95 & 18 & Biforza & 2.8 & 112 & 20 \\
\hline The Lafan & 1.9 & 118 & 19 & St. Johann & 2.8 & 134 & 24 \\
\hline Korbfüller & 1.9 & 108 & 23 & Asker & 2.8 & 179 & 22 \\
\hline Proma & 1.9 & 77 & 14 & Jatsi & 2.8 & 66 & 16 \\
\hline Rumla & 2.0 & 171 & 34 & Fertödi Karmin & 2.8 & 102 & 22 \\
\hline Haida $^{a}$ & 2.0 & 107 & 15 & Gevalo & 2.8 & 84 & 18 \\
\hline Summit & 2.0 & 53 & 10 & Burgund & 2.8 & 33 & 10 \\
\hline Malling Seedling & 2.0 & 129 & 23 & Reflamba & 2.8 & 53 & 12 \\
\hline Loganlike & 2.0 & 100 & 20 & Tadmor & 2.8 & 155 & 22 \\
\hline Fertödi Zamatos & 2.1 & 109 & 20 & Wilkran/Framita ${ }^{\circledR}$ & 2.8 & 136 & 22 \\
\hline Glen Fyne & 2.1 & 102 & 16 & Isabell & 2.9 & 129 & 28 \\
\hline Polana & 2.1 & 99 & 21 & Glen Moy ${ }^{\mathrm{a}}$ & 2.9 & 38 & 10 \\
\hline Korfu Wonder & 2.1 & 127 & 20 & Malling Admiral & 2.9 & 145 & 27 \\
\hline Dulcita & 2.1 & 97 & 22 & Joan Squire & 2.9 & 80 & 17 \\
\hline Taylor & 2.1 & 101 & 18 & Glen Clova & 2.9 & 89 & 19 \\
\hline Himbeerquelle & 2.1 & 85 & 16 & Wei-Rula & 2.9 & 236 & 53 \\
\hline Himbeerkönigin & 2.2 & 223 & 33 & Streib2a & 2.9 & 124 & 34 \\
\hline Deep Purple & 2.2 & 51 & 8 & Erika & 2.9 & 146 & 18 \\
\hline Annamaria & 2.2 & 41 & 8 & Bulgarski Rubin & 2.9 & 130 & 24 \\
\hline Bois Blank & 2.3 & 60 & 13 & Glen Prosen & 2.9 & 91 & 20 \\
\hline Comtesse & 2.3 & 217 & 45 & Pokusa & 2.9 & 12 & 4 \\
\hline Seneca & 2.3 & 133 & 18 & Sumo2 & 2.9 & 61 & 14 \\
\hline Ariadne & 2.3 & 53 & 12 & Kronprinz & 2.9 & 92 & 17 \\
\hline Milton & 2.3 & 153 & 22 & Clutha & 2.9 & 74 & 14 \\
\hline Vene & 2.3 & 98 & 17 & Josephine & 3.0 & 166 & 29 \\
\hline Zenit & 2.3 & 47 & 11 & Rubaca/Niniane $^{\circledR}$ & 3.0 & 50 & 14 \\
\hline Nagymarosi & 2.3 & 141 & 18 & Immertragende von Feldbrunn & 3.0 & 124 & 20 \\
\hline
\end{tabular}


Table 2 continued

\begin{tabular}{|c|c|c|c|c|c|c|c|}
\hline Cultivar & AR & $\Sigma$ Canes & $\Sigma$ Plants & Cultivar & $\mathrm{AR}$ & $\Sigma$ Canes & $\Sigma$ Plants \\
\hline Holyoke & 2.3 & 48 & 15 & Dinkum & 3.0 & 199 & 34 \\
\hline Caliber & 2.3 & 70 & 18 & Motoeka & 3.0 & 160 & 26 \\
\hline Royal Scott & 2.3 & 72 & 10 & Salviraspa & 3.0 & 99 & 16 \\
\hline Tola & 2.3 & 12 & 1 & Pechts Herbstfreude & 3.0 & 105 & 22 \\
\hline Matterhorn & 2.4 & 99 & 18 & Nootka $^{\mathrm{a}}$ & 3.0 & 79 & 14 \\
\hline Aromquee & 2.4 & 177 & 33 & Pechts Gigant & 3.0 & 65 & 15 \\
\hline Gigant & 2.4 & 148 & 21 & Rafzaqu/Himbo Top ${ }^{\circledR}$ & 3.0 & 38 & 11 \\
\hline Stuttgart & 2.4 & 133 & 19 & B. Seedling & 3.1 & 131 & 26 \\
\hline Rutrago/Rucanta ${ }^{\circledR}$ & 2.4 & 86 & 16 & Veten & 3.1 & 31 & 8 \\
\hline Newburgh & 2.4 & 99 & 16 & Redwing & 3.1 & 63 & 12 \\
\hline Octavia & 2.4 & 31 & 11 & Malahat & 3.1 & 256 & 50 \\
\hline Gelbe Antwerpen & 2.4 & 95 & 18 & Fallgold & 3.1 & 84 & 20 \\
\hline Brandywine & 2.4 & 87 & 14 & Brilliance & 3.1 & 117 & 24 \\
\hline Viking & 2.4 & 87 & 14 & Poranna Rosa & 3.1 & 89 & 18 \\
\hline Chilcotin $^{\mathrm{a}}$ & 2.4 & 71 & 11 & Rafzelsa/Himbostar ${ }^{\circledR}$ & 3.1 & 36 & 8 \\
\hline Glen Ample & 2.4 & 254 & 56 & Rode Radboud & 3.1 & 88 & 14 \\
\hline Selectie Eversdijk & 2.4 & 100 & 15 & Watson/Ruby ${ }^{\circledR}$ & 3.2 & 33 & 8 \\
\hline Tragilo & 2.4 & 92 & 15 & Rumilo & 3.2 & 114 & 20 \\
\hline Mayfair & 2.4 & 79 & 15 & Gloria & 3.2 & 13 & 4 \\
\hline Andenken an Paul Camenzind & 2.4 & 67 & 9 & Malling Promise & 3.2 & 123 & 22 \\
\hline September & 2.4 & 156 & 25 & Carmelina & 3.2 & 181 & 33 \\
\hline Saxa Record & 2.4 & 97 & 15 & Herbert & 3.2 & 60 & 13 \\
\hline Julia & 2.5 & 30 & 8 & Malling Leo & 3.2 & 12 & 3 \\
\hline Malling Landmark & 2.5 & 147 & 25 & Gradina & 3.2 & 53 & 15 \\
\hline Jochems Roem & 2.5 & 101 & 13 & Geloy & 3.2 & 75 & 17 \\
\hline Meeker $^{\mathrm{a}}$ & 2.5 & 271 & 49 & Sirius & 3.2 & 106 & 20 \\
\hline NZEH & 2.5 & 81 & 16 & Francesca & 3.2 & 41 & 10 \\
\hline Glen Rosa & 2.5 & 61 & 14 & Titan & 3.3 & 59 & 18 \\
\hline Zefa1 & 2.5 & 104 & 17 & Willamette $^{\mathrm{a}}$ & 3.3 & 58 & 10 \\
\hline Spica & 2.5 & 65 & 14 & Tambar & 3.3 & 97 & 19 \\
\hline Polka & 2.5 & 107 & 17 & Hitra & 3.3 & 96 & 16 \\
\hline Ida & 2.5 & 8 & 4 & Rumiloba & 3.3 & 64 & 18 \\
\hline Amity & 2.5 & 168 & 23 & Comox & 3.3 & 68 & 16 \\
\hline Tulameen & 2.5 & 235 & 59 & Preussen & 3.3 & 102 & 21 \\
\hline Rafzmach/Elida $^{\circledR}$ & 2.5 & 53 & 18 & Frosta & 3.3 & 110 & 22 \\
\hline Norfolk Gigant & 2.5 & 41 & 10 & Dauerpreussen & 3.3 & 134 & 20 \\
\hline Norprins & 2.5 & 74 & 12 & Metzer Zucker & 3.3 & 67 & 16 \\
\hline Köstliche Selita & 2.5 & 129 & 26 & Deutschland 1 & 3.4 & 94 & 18 \\
\hline Nordmark & 2.5 & 101 & 20 & Norna & 3.4 & 41 & 12 \\
\hline Balder & 2.6 & 123 & 19 & Rucami & 3.4 & 49 & 14 \\
\hline Cardinal & 2.6 & 130 & 31 & Resa/Lucana ${ }^{\circledR}$ & 3.5 & 35 & 11 \\
\hline Lagorai & 2.6 & 95 & 15 & Malling Delight & 3.5 & 43 & 12 \\
\hline Phyllis King & 2.6 & 67 & 10 & Qualicum & 3.5 & 117 & 32 \\
\hline Autumn Bliss & 2.6 & 301 & 51 & Varnes & 3.5 & 127 & 13 \\
\hline Fetödi Venus & 2.6 & 144 & 25 & Gelbe Siebenkugel & 3.5 & 76 & 14 \\
\hline
\end{tabular}


Table 2 continued

\begin{tabular}{lccclccc}
\hline Cultivar & AR & $\Sigma$ Canes & $\Sigma$ Plants & Cultivar & AR & $\Sigma$ Canes & $\Sigma$ Plants \\
\hline Zefa2 & 2.6 & 105 & 21 & Framita & 3.5 & 26 & 10 \\
Golden Bliss & 2.6 & 99 & 17 & Riesen Industrie & 3.6 & 81 & 16 \\
Orange Marie & 2.6 & 61 & 10 & Doppelernte & 3.6 & 52 & 11 \\
Skeena & 2.6 & 51 & 10 & Fallred & 3.6 & 60 & 14 \\
St. Peter & 2.6 & 57 & 12 & Bauer 61 & 3.6 & 37 & 6 \\
Joan J & 2.6 & 96 & 16 & Maravilla & 3.7 & 81 & 18 \\
Tea & 2.7 & 20 & 6 & Chiliwak & 3.7 & 32 & 6 \\
Saxa Bliss & 2.7 & 82 & 14 & Madawaska & 3.8 & 72 & 16 \\
Pechts Record & 2.7 & 109 & 16 & Canby & 3.9 & 42 & 8 \\
Heja & 2.7 & 102 & 14 & Delmes & 4.0 & 41 & 10 \\
\hline
\end{tabular}

Sampling was performed as shown in Supplementary Table 1

Cultivar, genotype evaluated; AR, average rating; $\Sigma$ Canes, total number of canes evaluated for this genotype; $\Sigma$ Plants, total number of plants evaluated

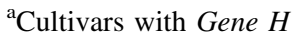

24 different fungi from two locations in Saxony (eastern Germany). Twenty-three out of these cane associated fungi were present at location 1 , whereas ten out of them were present at location 2, which is $100 \mathrm{~km}$ away from location 1 . Importantly, pathogens known to be involved in raspberry cane diseases such as $F$. avenaceum, $L$. coniothyrium, $D$. applanata and Botrytis sp. were consistently (at all time points) found at both locations. Therefore, fungi found at both locations are more likely to be the primary causal pathogens of cane disease in Saxony. The occurrence of these fungi may depend on many factors, including seasonal fluctuations. Hence, we looked at the composition of fungi occurring on naturally infected raspberry canes in the field at different time points (May, June, August and October) in 2014. Interestingly, we found that incidences of the classical cane disease causing fungi, such as D. applanata, Botrytis sp. and Leptosphaeria sp. decreased during the season, whereas the incidence of $F$. avenaceum increased (Fig. 1). This might be a further indication that this fungal species is mainly responsible for cane disease in eastern Germany. Together with $F$. avenaceum, the incidence of $A$. alternata increased as well and dominated during summer (Fig. 1). Typically, species of the genus Alternaria are saprophytes and $A$. alternata has been suggested to be the most common fungus on the surface of raspberry canes (Ruokola 1982). However, several species of the genus $A l$ ternaria have been described as plant pathogens. This is particularly true for various pathovars of $A$. alternata that are able to infect more than 100 host plants (Rotem 1994; Thomma 2003). Future studies will reveal, whether A. alternaria indeed behaves saprophytic on raspberry canes or if some pathovars are capable of infecting raspberry canes and, thus, contribute to cane diseases. On the other hand, $F$. avenaceum has been shown to be the main pathogen causing cane disease in northern Germany, which is thought to occur either independently or in combination with the cane midge $R$. theobaldi (Weber and Entrop 2008). The high proportion of $F$. avenaceum found on diseased raspberry canes, especially in August and October in the present study, suggests that the observation of Weber and Entrop (2008) may hold true for eastern Germany as well. This is in contrast to other European countries, where $F$. avenaceum appears to play a minor role in the development of cane disease and is mainly involved as one pathogen (amongst others) in the midge blight complex (Hall et al. 2009). 

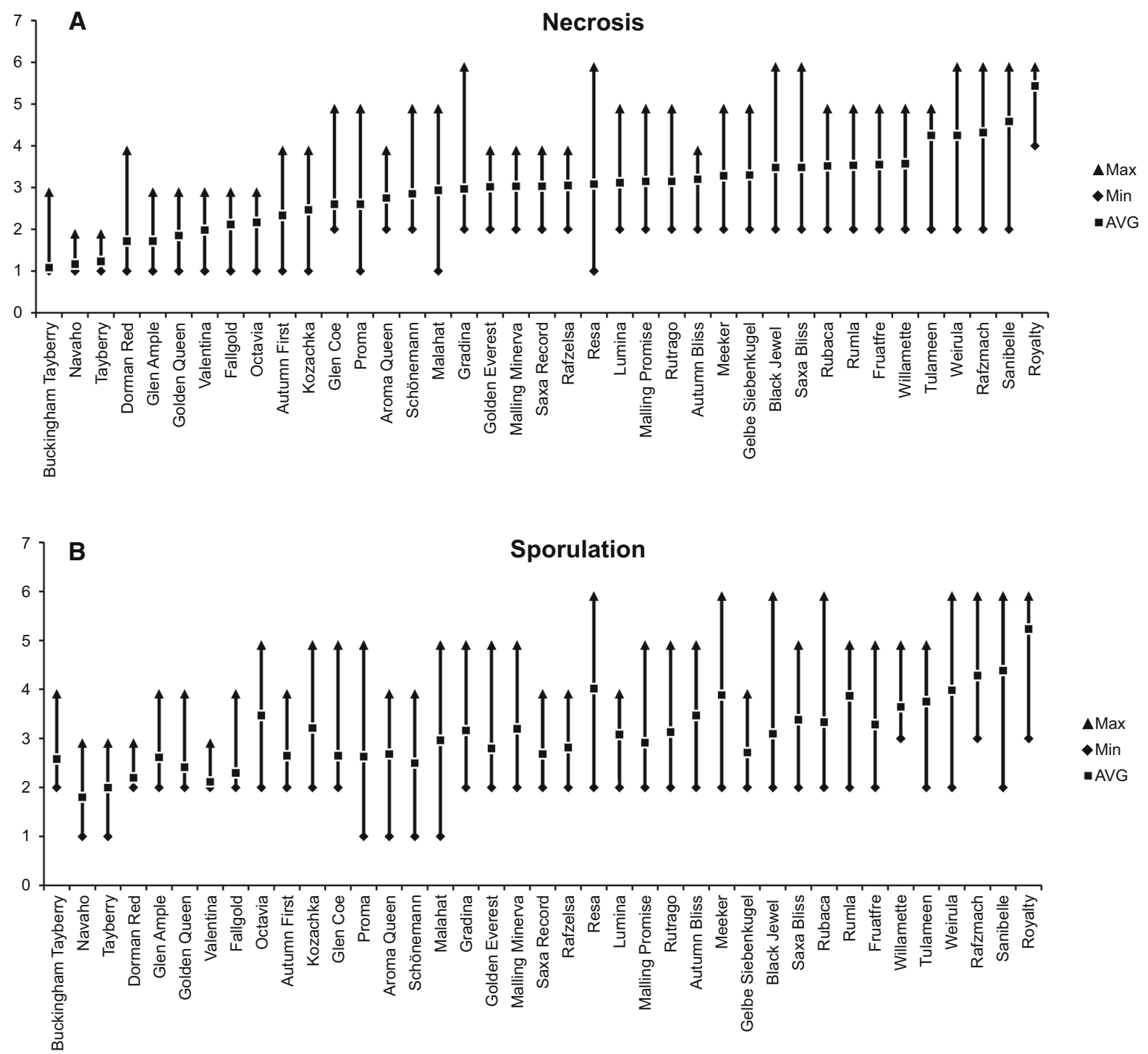

Fig. 3 In vitro inoculation of primocane raspberry canes with Fusarium avenaceum (2013-2014). Mean values of rating from 2013-2014 are shown. Rating values correspond to the scale defined in Supplementary Figure 2. A Occurence of necrotic

Scoring Rubus genetic resources for resistance to cane diseases

By using a rating scale, we evaluated 213 raspberry cultivars at two locations in Saxony after natural infection in the field. This collection represents the majority of Rubus germplasm available to raspberry breeding in Germany. In both locations, it was apparent that possible sources for resistance were mainly found in Rubus hybrid cultivars (e.g. 'Dorman tissue. B Sporulation. Average values for the rating of each cultivar are shown as squares. Maximum and minimum rating values for each cultivar are depicted as triangles and diamonds, respectively

Red', 'Glen Coe', 'Tayberry' or 'Buckingham Tayberry') or closely related Rubus species (Rubus occidentalis with the cultivars 'Lowden' and 'Black Jewel') (Fig. 1, Table 2).

It is difficult to give authoritative reasons behind the broad susceptibility towards cane diseases observed in $R$. idaeus cultivars. One major reason for the lack of resistance sources within $R$. idaeus might be a consequence of the genetic erosion during domestication and the genetic similarity of today's 

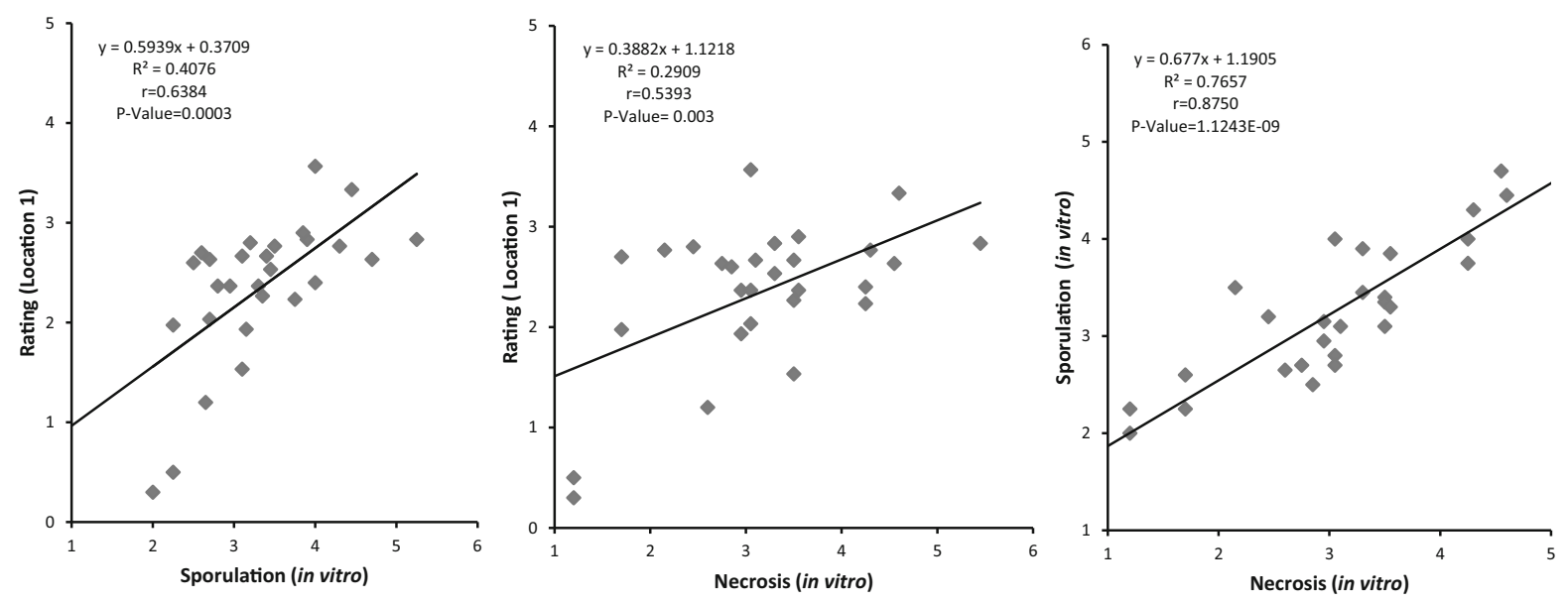

Fig. 4 Correlation of in vitro parameters with field data from location 1, Borthen and between in vitro parameters. Rating values of 28 cultivars rated at location 1, Borthen (2012-2014) and in in vitro-inoculation experiments (2013-2014) were used. $\mathrm{y}=$ function of the linear regression; $\mathrm{R}^{2}=$ coefficient of determination; $r=$ correlation coefficient (Pearson). $\mathrm{H}_{0}=$ testing hypothesis $=$ both parameters are statistically insignificantly correlated. $\mathrm{H}_{\mathrm{A}}=$ alternative hypothesis $=\mathrm{a}$ statistically

raspberry cultivars (Dale et al. 1993; Jennings 1988). This can explain why sources of resistance are mainly found in closely related Rubus species or their hybrid offspring.

Additionally, historical reports showed that raspberry cultivars with pubescent canes (Genotype $H h$ ) were more resistant towards cane diseases caused by B. cinerea, D. applanata and L. coniothyrium (White et al. 1990). In this study, cultivars carrying gene $H$ (Jennings and McGregor 1988) ranged from 2.0 ('Haida'), to 3.9 ('Canby') for cane disease resistance (Table 2). Hence, gene $H$ appears to have little influence on the degree of field resistance towards cane disease in the tested field plots. These results support our speculation that $D$. applanata, B. cinerea and $L$. coniothyrium might play a minor role in the manifestation of cane diseases in Saxony.

Cane splitting of variable intensities are frequently found in raspberry cultivars, and wounds might represent entry sites of various fungi or the cane midge Reselliella theobaldi, which can promote midge blight (Vétek et al. 2006; Woodhead et al. 2013). Therefore, part of the susceptibility might be caused by a cultivar's propensity for cane splitting (Woodhead et al. 2013).

Since natural infection is strongly influenced by environmental cues, we developed inoculation tests significant correlation between both parameters exists. a correlation between sporulation (in vitro) and rating (Borthen). $p<0.01(p=0.0003)$, the correlation is significant. b correlation between necrosis (in vitro) and rating (Borthen). $p<0.01$ $(p=0.003)$, the correlation is significant. c correlation between necrosis (in vitro) and rating (Borthen). $p<0.01$, $(p=0.000000001)$ the correlation is significant

that allow controlled and directed infections. A major advantage of these methods is the quick assessment with individual pathogens under a standardized environment. Our in vitro testing method developed for this study circumvents the need of naturally occurring cane splitting by artificially wounding canes and inoculating with $F$. avenaceum. Sporulation and necrosis after artificial inoculation of field grown primocane pieces in the in vitro test were significantly correlated with data collected after natural infection in the field (Fig. 4), demonstrating the applicability of this test and supporting the speculation that $F$. avenaceum is the primary causal pathogen. We observed that infection success of $F$. avenaceum depends on wounds (openings), thus supporting the observation that natural openings (e.g. split canes) facilitate natural infection with $F$. avenaceum in the field (Woodhead et al. 2013). Some cultivars (e.g. 'Tayberry', 'Buckingham Tayberry' or 'Valentina') allowed very little to no sporulation of $F$. avenaceum in the in vitro assay (Fig. 3), indicating that a mechanism of quantitative disease resistance might stop propagation of $F$. avenaceum in those cultivars even if this first barrier has been surpassed by wounding or splitting of canes in the field.

The highest degree of resistance in vitro as well as in the field was found in the Rubus hybrid cultivars 
Table 3 List of all 36 Rubus genotypes used to assess ploidy levels

\begin{tabular}{|c|c|c|}
\hline Cultivar & Pedigree & Ploidy \\
\hline \multicolumn{3}{|l|}{ Raspberry } \\
\hline Aroma Queen & Autumn Bliss open pollinated & $2 \mathrm{n}=2 \mathrm{x}$ \\
\hline Autumn Bliss & Complex parentage includes Lloyd George, $R$. ideaus strigosus, $R$. arcticus, $R$. occidentalis & $2 \mathrm{n}=2 \mathrm{x}$ \\
\hline Black Jewel & $($ Bristol $\times$ Dundee $) \times$ Dundee & $2 n=2 x$ \\
\hline Dorman Red & Rubus parvifolius L. $\times$ Dorsett & $2 n=2 x$ \\
\hline Rafzmach/Elida ${ }^{\circledR}$ & Malling Admiral $\times$ Chilcotin & $2 n=2 x$ \\
\hline $\begin{array}{l}\text { Gelbe } \\
\text { Antwerpener }\end{array}$ & Unknown & $2 \mathrm{n}=2 \mathrm{x}$ \\
\hline Glen Ample & Derivative of G. Prosen, Meeker, Preussen, M. Promise 'SCRI 7326E1' × 'SCRI 7412H' & $2 \mathrm{n}=2 \mathrm{x}$ \\
\hline Glen Coe & 'SCRI 7751C4' × Glen Prosen & $2 n=2 x$ \\
\hline Gradina & Malling Exploit $\times$ Rubin & $2 n=2 x$ \\
\hline $\begin{array}{l}\text { Rafzelsa/ } \\
\text { Himbostar }^{\circledR}\end{array}$ & Rote Wädenswiler open pollinated & $2 n=2 x$ \\
\hline Kozachka & Blagorodna $\times$ Shtambovyi-19 & $2 \mathrm{n}=2 \mathrm{x}$ \\
\hline Resa/Lucana ${ }^{\circledR}$ & Unknown & $2 n=2 x$ \\
\hline Lumina & Unknown & $2 n=2 x$ \\
\hline Malahat & Meeker $\times$ BC/SCRI 7853/116 & $2 n=2 x$ \\
\hline Malling Promise & Newburgh $\times($ Lloyd George $\times$ Pyne's Royal $)$ & $2 n=2 x$ \\
\hline Meeker & Willamette $\times$ Cuthbert & $2 n=2 x$ \\
\hline Oktavia & Malling Hestia $\times$ Glen Ample & $2 n=2 x$ \\
\hline Polana & Heritage $\times$ Zeva Herbsternte & $2 n=2 x$ \\
\hline Polesie & & $2 n=2 x$ \\
\hline Polka & & $2 n=2 x$ \\
\hline Radziejowa & & $2 n=2 x$ \\
\hline Malling Minerva & $\begin{array}{l}\text { Complex parentage including M. Promise, } R \text {. crataegifolius, } R \text {. occidentalis, } R \text {. idaeus } \\
\text { strigosus } \times \text { SCRI 7269/67 }\end{array}$ & $2 n=2 x$ \\
\hline Royalty & N.Y. $252 \times$ N.Y. 17861 & $2 n=2 x$ \\
\hline Rubaca/Niniane ${ }^{\circledR}$ & Rutrago $\times$ Latham & $2 \mathrm{n}=2 \mathrm{x}$ \\
\hline Rumla & Unknown & $2 n=2 x$ \\
\hline Saxa Record & Autumn Bliss open pollinated & $2 n=2 x$ \\
\hline Schönemann & Lloyd George $\times$ Preußen & $2 n=2 x$ \\
\hline Tarusa & Shtambovyi-1 $\times$ Stolichnaya & $2 n=2 x$ \\
\hline Tula Magic & Autumn Bliss $\times$ Tulameen & $2 n=2 x$ \\
\hline Tulameen & Nootka $\times$ Glen Prosen & $2 n=2 x$ \\
\hline Wei-Rula & Rutrago $\times$ Latham & $2 n=2 x$ \\
\hline Willamette & Newburgh $\times$ Lloyd George & $2 n=2 x$ \\
\hline Zoltij Gigant & Maroseika $\times$ Ivanovskaya & $2 n=2 x$ \\
\hline \multicolumn{3}{|l|}{ Other Rubus species } \\
\hline $\begin{array}{l}\text { Buckingham } \\
\text { Tayberry }\end{array}$ & Spine-free sports of 'Tayberry' & $2 n=6 x$ \\
\hline Navaho & Ark. $583($ Thornfree $\times$ Brazos $) \times$ Ark. $631($ Ark. $550 \times$ Cherokee $)$ & $2 \mathrm{n}=4 \mathrm{x}$ \\
\hline Tayberry & Aurora $(2 n=8 x+2=58) \times$ SCRI $626 / 67(2 n=4 x=28)$ & $2 n=6 x$ \\
\hline
\end{tabular}


'Tayberry', 'Buckingham Tayberry' and 'Dorman Red'. Hence, these three cultivars might be well suited for future breeding programs. However, both 'Tayberry' types are hybrid offspring of the blackberry 'Aurora' $(2 n=8 x+2=58)$ and the tetraploid raspberry breeding clone 'SCRI 626/67' (Thompson 1995). Moreover, 'Dorman Red' is a hybrid of $R$. idaeus cv. 'Dorsett' $(2 n=2 x=14)$ and $R$. parvifolius $(2 n=2 x=14$ or $2 n=4 x=28)$. Because inter-ploidy crosses are often difficult and in order to avoid possible disturbances in future crosses (e.g. problems in chromosome pairing known for inter-ploidy crosses), we evaluated ploidy level of the Rubus genotypes available the Julius Kühn-Institut in Dresden. 'Tayberry' and 'Buckingham Tayberry' are hexaploid $(6 \times)$ and the blackberry cultivar 'Navaho' is tetraploid $(4 \times)$ (Table 3), (Meng and Finn 2002; Thompson 1995). However, the Rubus hybrid cultivar 'Dorman Red' was found to be diploid. Thus, it provides a valuable source of resistance introgression into red raspberry ( $R$. idaeus) germplasm. Other sources of resistance, which have not been tested in this study might be found in wild $R$. idaeus germplasm (Hall et al. 2009). As of now, the genetic architecture of the field resistance displayed in the above cultivars is unknown. Several studies have identified sources of field resistance against multiple pathogens in numerous other plant species which can be contributed by individual major effect QTL or multiple minor effect QTL (Wiesner-Hanks and Nelson 2016).

In general, future breeding programs for resistance to cane diseases in Germany should encompass a combined strategy. Diploid germplasm of related, intercrossable Rubus species (e.g. 'Dorman Red') or wild $R$. idaeus accessions should be used to widen the gene pool of raspberries. Moreover, breeding programs employing marker assisted selection should focus on breeding of cultivars with little tendency towards cane splitting (Woodhead et al. 2013), resistance towards cane midge and towards $F$. avenaceum upon artificial (in vitro) inoculation. Steadily decreasing costs of genomic sequencing make it feasible to map quantitative trait loci (QTL) by association mapping in germplasm collections and conventional QTL mapping in suitable bi-parental mapping populations. Using these techniques, QTLs for resistance towards cane midge and resistance towards $F$. avenaceum after wounding and artificial (in vitro) inoculation could be found and molecular markers derived for breeding purposes.

Acknowledgements We gratefully acknowledge the Federal Ministry of Food and Agriculture (BMEL) for the financial support (Project Number: 511-06.01-28-1-45.055-10) in the frame of supporting innovation in plant breeding by the Federal Office for Agriculture and Food (BLE). We would also like to express our gratitude to G. Beck (Beck's Obsthof Borthen) and Dr. O. Krieghoff (Erzeugerorganisation Dresdener Obst) for cooperating with us on this project. We are also grateful to $\mathrm{N}$. Richelhof, S. Bartsch, I. Polster and V. Vogt for technical assistance, Dr. A. Peil for scientific advice and A. Zschammer (Bundessortenamt-Experimental Station Wurzen, Germany) for providing us with plant material and for helpful discussions. We also acknowledge Dr. F. O. Emeriewen for improving the English language of the manuscript.

\section{Compliance with ethical standards}

Conflict of interest The authors declare that they have no conflict of interest.

Open Access This article is distributed under the terms of the Creative Commons Attribution 4.0 International License (http:// creativecommons.org/licenses/by/4.0/), which permits unrestricted use, distribution, and reproduction in any medium, provided you give appropriate credit to the original author(s) and the source, provide a link to the Creative Commons license, and indicate if changes were made.

\section{References}

Dale A, Moore PP, McNicol RJ, Sjulin TM, Burmistrov LA (1993) Genetic diversity of red raspberry varieties throughout the-world. J Am Soc Hortic Sci 118:119-129

Faostat (2016) Agriculture Organization of the United Nations. http://www.fao.org/faostat/en/\#data/QC. Date Apr 2015

Graham J, Smith K, Tierney I, MacKenzie K, Hackett CA (2006) Mapping gene $\mathrm{H}$ controlling cane pubescence in raspberry and its association with resistance to cane botrytis and spur blight, rust and cane spot. Theor Appl Genet 112:818-831

Graham J, Hackett CA, Smith K, Woodhead M, MacKenzie K, Tierney I, Cooke D, Bayer M, Jennings N (2011) Towards an understanding of the nature of resistance to Phytophthora root rot in red raspberry. Theor Appl Genet 123:585-601

Hall HK, Hummer KE, Jamieson AR, Jennings SN, Weber CA (2009) Raspberry breeding and genetics. In: Janick J (ed) Plant breeding reviews. Wiley, Hoboken, pp 39-353

Jennings DL (1962) Some evidence on the influence of the morphology of raspberry canes upon their liability to be attacked by certain fungi. Hortic Res 1:100-111

Jennings DL (1982) Resistance to Didymella applanata in red raspberry and some related species. Ann Appl Biol 101:331-337 
Jennings DL (1988) Raspberries and blackberries: their breeding, diseases and growth. Academic Press, London. ISBN 0123842409

Jennings DL, Brydon E (1989a) Further studies on breeding for resistance to Botrytis cinerea in red raspberry canes. Ann Appl Biol 115:507-513

Jennings DL, Brydon E (1989b) Further studies on resistance to Leptosphaeria coniothyrium in the red raspberry and related species. Ann Appl Biol 115:499-506

Jennings DL, McGregor GR (1988) Resistance to cane spot (Elsinoë veneta) in the red raspberry and its relationship to resistance to yellow rust (Phragmidium rubi-idaei). Euphytica 37:173-180

Konstantinova P, Bonants PJM, Van Gent-Pelzer MPE, Van Der Zouwen P, Van Den Bulk R (2002) Development of specific primers for detection and identification of $\mathrm{Al}$ ternaria spp. in carrot material by PCR and comparison with blotter and plating assays. Mycol Res 106:23-33

Lindqvist-Kreuze H, Hellqvist S, Koponen H, Valkonen JPT (2003) Phoma-Didymella complex on hybrid arctic bramble with wilting symptoms. Plant Pathol 52:567-578

Meng R, Finn C (2002) Determining ploidy level and nuclear dna content in Rubus by flow cytometry. J Am Soc Hortic Sci 127:767-775

Mishra PK, Fox RTV, Culham A (2003) Development of a PCRbased assay for rapid and reliable identification of pathogenic Fusaria. FEMS Microbiol Lett 218:329-332

Rigotti S, Gindro K, Richter H, Viret O (2002) Characterization of molecular markers for specific and sensitive detection of Botrytis cinerea Pers.: Fr. in strawberry (Fragaria $\times$ ananassa Duch.) using PCR. FEMS Microbiol Lett 209:169-174

Rotem J (1994) The genus Alternaria: biology, epidemiology, and pathogenicity. APS Press, University of Michigan, Ann Arbor. ISBN 0890541523
Ruokola LA (1982) Fungus diseases of raspberry (Rubus idaeus L.) in Finland [Phoma sp., Didymella applanata]. J Sci Agric Soc Finl 54(2):99-111

Rupp S, Weber RWS, Rieger D, Detzel P, Hahn M (2016) Spread of Botrytis cinerea strains with multiple fungicide resistance in German horticulture. Front Microbiol 7:2075

Thomma BPHJ (2003) Alternaria spp.: from general saprophyte to specific parasite. Mol Plant Pathol 4:225-236

Thompson MM (1995) Chromosome numbers of Rubus cultivars at the national clonal germplasm repository. HortScience 30:1453-1456

Vétek G, Fail J, Pénzes B (2006) Susceptibility of raspberry cultivars to the raspberry cane midge (Resseliella theobaldi BARNES). J Fruit Ornam Plant Res 14:61-66

Weber RWS, Entrop A-P (2008) Fusarium avenaceum, Haupterreger der Himbeerrutenkrankheit in Norddeutschland. Erwerbs-Obstbau 50:109-115

White TJ, Bruns T, Lee SJWT, Taylor JL (1990) Amplification and direct sequencing of fungal ribosomal RNA genes for phylogenetics. In: Innis MA, Gelfand DH, Sninsky JJ, White TJ (eds) PCR protocols: a guide to methods and applications. Academic Press, New York, pp 315-322

Wiesner-Hanks T, Nelson R (2016) Multiple disease resistance in plants. Annu Rev Phytopathol 54:229-252

Williamson B, Hargreaves AJ (1979) Fungi on red raspberry from lesions associated with feeding wounds of cane midge (Resseliella theobaldi). Ann Appl Biol 91:303-307

Woodhead M, Williamson S, Smith K, McCallum S, Jennings N, Hackett C, Graham J (2013) Identification of quantitative trait loci for cane splitting in red raspberry (Rubus idaeus). Mol Breed 31:111-122 